DEMOGRAPHIC RESEARCH

VOLUME 38, ARTICLE 21, PAGES 513-548

PUBLISHED 13 FEBRUARY 2018

http://www.demographic-research.org/Volumes/Vol38/21/

DOI: 10.4054/DemRes.2018.38.21

Research Material

Design and implementation of a high-quality probability sample of immigrants and ethnic minorities: Lessons learnt

Peter Lynn

Alita Nandi

Violetta Parutis

Lucinda Platt

(C) 2018 Peter Lynn, Alita Nandi, Violetta Parutis \& Lucinda Platt.

This open-access work is published under the terms of the Creative Commons Attribution 3.0 Germany (CC BY 3.0 DE), which permits use, reproduction, and distribution in any medium, provided the original author(s) and source are given credit.

See https://creativecommons.org/licenses/by/3.0/de/legalcode. 


\section{Contents}

1 Introduction $\quad 514$

2 Background: Approaches to sampling migrants 516

3 Designing a representative sample of immigrants and ethnic 519

$3.1 \quad$ Context 519

3.2 Boosting the immigrant and ethnic minority sample of UKHLS $\quad 520$

3.3 Sampling strategy 521

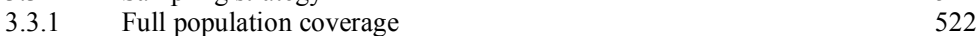

3.3.2 Coverage of the boost samples 523

3.3.3 Sampling strata and sampling fractions $\quad 523$

$\begin{array}{ll}\text { 3.3.4 Overall statistical efficiency } & 526\end{array}$

$4 \quad$ Implementing the immigrant and ethnic minority survey 528

$4.1 \quad$ Screening and interviewing 528

$\begin{array}{ll}4.2 & \text { Fieldwork procedures } \\ \end{array}$

$5 \quad$ Results 531

$5.1 \quad$ Household response 531

$\begin{array}{ll}5.2 \text { Individual response } & 532\end{array}$

$6 \quad$ Sample description $\quad 533$

6.1 Target and achieved samples $\quad 533$

6.2 Quality of coverage of the Understanding Society sample in wave $6 \quad 536$ $(2014 / 15)$

7 Conclusions $\quad 538$

$\begin{array}{ll}\text { References } & 541\end{array}$

$\begin{array}{ll}\text { Appendix } & 545\end{array}$ 


\title{
Design and implementation of a high-quality probability sample of immigrants and ethnic minorities: Lessons learnt
}

\author{
Peter Lynn ${ }^{1}$ \\ Alita Nandi ${ }^{1}$ \\ Violetta Parutis ${ }^{1}$ \\ Lucinda Platt ${ }^{2}$
}

\begin{abstract}
BACKGROUND

Surveys of immigrants face challenges of coverage, representativeness, and response rates. Longitudinal studies of immigrants and ethnic minorities, which have potential to address pressing issues in demographic research, are rare or partial. In the absence of register data, the highest quality approach is argued to be probability sampling using household screening.
\end{abstract}

\section{OBJECTIVE}

To describe the design and implementation of a nationally representative probability sample of immigrants and ethnic minorities in the United Kingdom.

\section{METHODS}

We boosted a nationally representative sample by using small-area census data to identify areas that covered the majority of immigrant and target ethnic minority populations and oversampled addresses from those areas using varying sampling fractions. Households were screened for eligibility based on whether they included a target immigrant/ethnic minority member. If so, all adult members were interviewed.

\section{RESULTS}

We anticipated the main challenges would be: fewer eligible households than predicted in sampled areas due to geographical mobility; refusal of those screened to provide information on household eligibility; nonparticipation of eligible households. All these issues were found to some degree. We describe how we addressed them and with what success.

\footnotetext{
${ }^{1}$ University of Essex, Colchester, UK.

${ }^{2}$ London School of Economics and Political Science, London, UK. Email: 1.platt@1se.ac.uk.
} 


\section{CONCLUSIONS}

A careful design and robust fieldwork practices can enable a two-stage probability sampling to achieve good coverage and a much more representative sample of immigrants and ethnic minorities than with more ad hoc methods. The potential research payoffs are substantial.

\section{CONTRIBUTION}

We demonstrate the potential for careful two-stage sampling on the back of an existing study for creating a high-quality multi-purpose survey of immigrants.

\section{Introduction}

Migration research is one of the most rapidly developing fields of demographic study in Europe. On the one hand, there is increasing attention paid to the outcomes of the children and grandchildren of immigrants, with development of theoretical perspectives to understand differentiated integration processes. On the other, patterns of migration to Europe have been evolving. Models of the traditional labour migrant have required modification in the light of, for example, the high levels of mobility following the European Union expansion; conflict-driven population movements and increases in refugees; the changing composition of migrants consequent on the shift from primary labour migration to family reunification and increasingly high-skilled 'managed' migration; and the evolution of countries such as Spain and Ireland from countries of emigration to countries of immigration.

To develop empirically-based theoretical understanding of contemporary immigration, and document both second-generation integration and changing forms of migration, requires high-quality representative data that both covers immigrant-origin populations of interest and incorporates relevant measures. As a result there has been a proliferation of studies, both national and cross-national, surveying specific immigrant or immigrant-origin populations. Some of these have focused on the second generation or the children of immigrants, such as the Integration of the European Second Generation (TIES) (Crul and Schneider 2010; Hornstra, Groenewold, and LessardPhillips 2012) or the Children of Immigrants Longitudinal Survey in Four European Countries (CILS4EU 2016); others have targeted those who are theoretically interesting given their recency of arrival (e.g., the SCIP survey; Diehl et al. 2016), and others have focused on populations of particular interest, such as Muslims or Poles (e.g., the 2004 Muslims in Europe (ME) study; Drinkwater and Garapich 2011). The two European Union minorities and discrimination surveys (EU-MIDIS and EU-MIDIS2) aimed to 
evaluate the extent of exclusion and discrimination faced by immigrants and minorities across Europe (European Union Fundamental Rights Agency 2009).

In some countries, comprehensive registration means that registers provide convenient sampling frames from which to sample, allowing for national coverage (such as the Netherlands sample of the SCIP study; Gresser and Schacht 2015) and/or for oversampling of particular groups, such as the recent immigrant and refugee studies carried out on the German Socio-Economic Panel (Brücker, Rother, and Schupp 2016). But in the absence of such registers (which is the case for most countries), researchers need to resort to other methods. These include both more systematic and more ad hoc methods, and typically require some trade-off between cost and coverage/representativeness. With pressure on research funding and in the face of declining response rates across the board - which are typically heightened for immigrant studies (Font and Mendez 2013; Platt, Luthra, and Frere-Smith 2015), researchers often have to work with a high degree of pragmatism in their approach to sampling, even if this limits the claims they can make for the ensuing data (Beauchemin and González-Ferrer 2011; Platt, Luthra, and Frere-Smith 2015). Nevertheless, it has been argued that the best possible approach to an immigrant population survey involves probability sampling using screening of households across areas in which immigrant populations are found in different densities (excluding, by necessity, the very lowest density areas) (Erens 2013; Font and Mendez 2013; Smith 1997). Such studies are costly especially where populations are dispersed or highly targeted, and may still lead to some unknowns about the extent to which the achieved sample is representative and includes the target groups, if non-cooperation with screening is substantial. But despite the costs and potential caveats, investing in the resources required for a high-quality study involving probability sampling and a two-stage screening approach is important for studies which are created as a resource for the wider academic community and which therefore need to command maximum scientific credibility and maximise the usability of data for a range of users. Arguably, the initial quality of the sample is particularly relevant if the sample is going to be followed up over time in a longitudinal study, with the same respondents being revisited over time.

In this paper we report on a high-quality survey of this kind: an immigrant and ethnic minority sample intended to be incorporated in the large, nationally representative study Understanding Society: The UK Household Longitudinal Study (UKHLS). We describe the design considerations and the approach to sampling, within the constraints of the funding available. Given the dispersion of immigrant and ethnic minority groups, this necessitated some compromise on coverage in order to focus on areas where there was a sufficiently high concentration to make screening viable in terms of cost. At the same time, the expected coverage - and hence representation - of immigrants and ethnic minorities living in diverse areas and circumstances was far 
higher than might be achieved by studies focusing only on those living in metropolitan areas (e.g., TIES, SCIP), which will not reflect the experience of those living outside such areas, or network based studies, which rely on group homogeneity (Tyldum and Johnston 2014).

We briefly discuss the development of the main questionnaire and the screening questionnaire before describing implementation in the field. We outline the three main challenges the study faced: (1) potential mismatch between the information on which the sample design was based (derived from the 2011 Census) and the actual distributions of immigrant and ethnic minority groups at the time of fieldwork in 2015; (2) reluctance of those screened to identify eligible households (and noncontact); (3) nonresponse of eligible households (or of individual respondents within responding households).

We discuss how we attempted to address these challenges both from the outset and throughout fieldwork before outlining response rates, our achieved sample, and its characteristics. While noting the limitations of this study, we reflect on the advantages of this data for addressing key research agendas going forward.

\section{Background: Approaches to sampling migrants}

The need to address pressing issues in migration research in Europe has led to the development of a wide range of surveys, with different approaches to meeting the challenges of obtaining robust representative samples of target groups of immigrants and ethnic minorities. Standard surveys typically contain insufficient numbers for analysis and may underrepresent key and less accessible groups, given that population sizes of immigrant populations as a whole and specific groups in particular are small and that immigrants tend to be more mobile than the population overall. In addition, response rates, which are declining across surveys as a whole, tend to be lower for minority groups, compounding problems of sample size and (potentially) representativeness (Font and Mendez 2013). Moreover, general purpose surveys often have limited coverage of questions relating specifically to research areas of interest to immigration scholars.

As a result, there has been a recent proliferation of immigrant-specific studies. Since sampling frames covering immigrants and specific ethnic groups are not widely available, these have used a range of approaches and techniques. Yet, despite variation in research focus, study design, and target populations (and sample sizes) all such studies had to contend with issues of representativeness, coverage, response rates, and inclusiveness (e.g., including those with rarely spoken languages). Maximising quality on these dimensions invariably necessitates some trade-off with cost. 
Those few countries that have population registers with relevant information can deploy them as sampling frames. For example in Germany the recent immigrant and refugee supplements to the German Socio-Economic Panel (SOEP) sampled from register data (Brücker, Rother, and Schupp 2016), while register data was used for identifying not only country of origin but also time of arrival for the Dutch and German samples for a study of recent immigrants in the Socio-Cultural Integration among New Immigrants Project (SCIP) (Gresser and Schacht 2015; Diehl et al. 2016). The linking of register information allows Statistics Netherlands to draw samples for social surveys based on the whole Dutch population and for specific subpopulations (Schmeets 2015). The French Longitudinal Survey of the Integration of First-time Arrivals (ELIPA) used information on receipt of a first residence permit to sample immigrants (Font and Mendez 2013). Sampling from the municipal-level population register ('Padron') is used for the National Immigrant Survey (ENI) in Spain (Duque, Ballano, and Pérez 2013). In the United Kingdom registers could be used to sample refugees (Burton and Lynn 2005), but other immigrant groups cannot be identified on registers.

However, even where such registers exist, they may not be ideal. First, in some countries they may not cover the second generation if they record country of origin rather than ethnicity or parental origins. Second, registers need to be maintained in order to provide up-to-date information about the location and circumstances of this mobile population. As a result, they usually work better as a sampling frame for more settled or stable populations.

Other studies have used a variety of approaches to retain some key features of probability sampling, albeit under certain conditions or for more specific populations. Some focus on the cities where the target populations, whether second generation or recent migrants, are most likely to live (e.g., TIES, the United Kingdom and Ireland samples of SCIP); others sample youth populations through schools (e.g., CILS4EU 2016); and others use chain-referral approaches (Tyldum and Johnston 2014; Platt, Luthra, and Frere-Smith 2015). Network (or multiplicity) sampling obtains information not only about the selected households but also relatives, neighbours, and others who may be connected to the household (Font and Mendez 2013). This technique, however, relies on the group of interest being well-networked, which may not necessarily be the case. One method that has been especially popular in Italy is centre sampling (Blangiardo 2008).

Some studies also use nonprobability sampling techniques in surveys of immigrants and ethnic minorities. These include snowballing, which is usually used where there are tight time or cost constraints (Hughes, Fenton, and Hine 1995; Kahan and Al-Tamimi 2009). A significant consideration when using snowballing is that it is likely to overrepresent individuals with numerous connections (Elliott et al. 2008) and introduce substantial bias (Kalton and Anderson 1986). Proportional quota sampling, a 
variant of snowballing, has also been used with some success (Drinkwater and Garapich 2011). Proportional quota sampling uses available datasets to identify the characteristics of the target population and then uses snowballing to sample the required numbers of the target population. Another nonrandom method is sampling from facilities such as community centres, churches, or workplaces. Although this method provides easier and cheaper access to the target population compared to other methods, it can introduce a considerable bias (Sudman and Kalton 1986; Magnani et al. 2005).

Where target populations are more dispersed, focused enumeration is sometimes employed - and can be used to supplement other methods employed in denser areas (e.g., Smith 1997). Focused enumeration relies on asking members of selected households to identify members of the target groups at adjacent addresses (Erens 2013). In spite of bringing down the costs of screening, this method has, however, been found to not boost overall numbers of the migrant population because migrants are not 'visible' enough in their local communities (Smith et al. 2011). Another way to increase cost-effectiveness in low-density areas is via an adaptive cluster design. If a target group resident is found at a sampled address, then additional addresses in the same street (e.g., neighbouring addresses) are also screened (e.g., Thompson 1990; Kalton and Anderson 1986; Sudman and Kalton 1986; Font and Mendez 2013).

While these numerous approaches to sample migrants may be more or less effective in particular circumstances and are often deployed pragmatically where there is no obvious way to sample the desired populations or where to do so would be prohibitively expensive, it has been argued that where registers are either unavailable or inappropriate for the targeted populations, sampling from those areas which cover most minorities, with screening of the resulting households to identify eligible respondents, is the best possible approach for achieving a probability sample with high coverage and representativeness (Erens 2013; Nazroo et al. 2005; Berthoud et al. 2009). Such twostage sampling with the selection of a random sample of addresses within the selected areas and subsequent screening is costly, even with careful design. But its potential payoffs are great in terms of the reliability of the sample, and its usability for multiple different research aims.

To be most effective, such two-stage sampling also needs to maximise response. However, there is ample evidence from immigrant studies to suggest that there are substantial challenges in engaging respondents and obtaining good response rates. Issues of trust, the relevance of the survey to participants, inclusivity via translation, and rigorous fieldwork processes are all likely to influence responses and sample size.

In sum, a high-quality probability sample of value for a wide range of research uses requires a careful design and robust fieldwork procedures to deliver representative samples of populations of interest. 


\section{Designing a representative sample of immigrants and ethnic minorities in the United Kingdom for longitudinal research}

\subsection{Context}

The United Kingdom offers a valuable case for analysing contemporary immigration and developing new insights into migration and integration processes for a number of reasons. First, as a former colonial power it maintained close relationships with and received immigrants from former colonies in the post-war peak migration periods. Thus, many labour migrants to the United Kingdom, especially in the early phase of post-war migration and high labour demand, were familiar with British institutions and had English as their first or one of their languages. At the same time, the diversity of the former colonies meant that migrants were arriving - and being sought from - widely differing country contexts and settled in areas with different levels of industrialisation and subject to different subsequent patterns of deindustrialisation and economic success. Primary migration for the main minority groups also peaked at different points, with Caribbean migration earlier and Bangladeshi and Black African migration later. These features of UK immigration offer the potential to distinguish between the experiences of different country of origin groups and investigate the role of different contexts of reception (Portes, Fernandez-Kelly, and Haller 2005).

Second, as the main migration period started in the 1950s, there are now substantial numbers of children (and grandchildren) from these different groups and phases of migration who have reached adulthood and allow examination of the experience of the second generation as well as of ongoing integration processes. The United Kingdom demonstrates both relatively socio-economically successful and relatively unsuccessful second-generation minorities, allowing for investigation of the circumstances under which outcomes differ.

Third, the United Kingdom has demonstrated a sharply shifting immigration regime. Initially all those from former colonies with British (overseas) passports were given residence rights with the British Nationality Act of 1948. But subsequent immigration controls restricted access, and most recently the United Kingdom demonstrates a 'managed migration' system that focuses on skilled migrants and requires high levels of economic resources for those seeking family reunification. This means that there have been phases of migration dominated by first labour migration, then family reunification, and then skilled migration (Luthra and Platt 2016). Most recently, students have formed a substantial proportion of migration flows into the United Kingdom even if most of these will be temporary (Luthra and Platt 2016).

Fourth, substantial immigration from European Union countries, especially following EU expansion from 2004, has changed the profile of more recent migrants, 
especially when considered in conjunction with immigration controls. For example, with much lower costs of immigration, the types of migrants self-selecting to move to the United Kingdom from the EU show diverse motivations (Luthra, Platt, and Salamonska 2016).

While there are commonalities with other European countries, the United Kingdom is in many ways at the extreme of the European cases in terms of, on the one hand, the stringency of its approach to managed migration and its limited reception of refugees, and on the other, the scale of recent East European migration. This makes it a valuable test bed for investigation of new migration formations and emerging theoretical accounts of processes.

Hence, while the immigrant and ethnic minority study described here is specific to the United Kingdom it is also likely to shed light on wider European processes and features of migration. This renders a study design that can incorporate both settled ethnic minority groups and more recent immigrants, that can capture the diversity of different groups and how their circumstances differ across different contexts, and which can follow processes of integration, adaptation, and reaction over time particularly valuable for providing an empirical bases for new developments in demographic migration research. Hence, when considering the targets for a boost sample to a large, high-quality nationally representative longitudinal sample of the United Kingdom, the design needed to cover established ethnic minority groups from key sending countries and arrival cohorts, from both the first (immigrant) and second generation, as well as more recent immigrants. The design needed also to cover as wide a variety of contexts as possible within the constraints of being restricted to relatively high-density areas.

\subsection{Boosting the immigrant and ethnic minority sample of UKHLS}

UKHLS is a large longitudinal survey that began data collection in January 2009 and interviews sample members and other members of their households annually (Buck and McFall 2012; Hobcraft and Sacker 2012). It had included a deliberate overrepresentation of ethnic minorities initially (Berthoud et al. 2009), but due to sample attrition the numbers of continuing respondents in some groups had declined over time. For example, while there were 1,435 adult Pakistani respondents at the first wave, there were only 1,089 by wave 5 , before the new boost was implemented; and while there were 1,405 Black African respondents at wave 1 there were only 827 at wave 5. Furthermore, households that had entered the United Kingdom since 2009 were necessarily excluded from the sample completely, and sample sizes of immigrants that were not in the study's target ethnic groups were relatively small, as people born outside of the United Kingdom had not been explicitly oversampled. Thus, the decision 
was taken to introduce a new sample in order to provide coverage of recent immigrants and substantially boost coverage of other immigrant and ethnic minority groups. This new sample is known as the Immigrant and Ethnic Minority Boost (IEMB) and is the subject of this paper. It was designed to be combined with the existing samples of persons of immigrant and ethnic minority background within UKHLS, and we refer to this combined sample as the Immigrant and Ethnic Minority Sample (UKHLS-IEMS). In Section 6 we describe the key features of this combined sample, following its boosting by the IEMB.

Target population groups for the IEMB were: (a) persons born outside of the United Kingdom, and (b) persons who consider themselves or their parents or grandparents to be of Indian, Pakistani, Bangladeshi, Black Caribbean, or Black African origin, which are the five largest established minority ethnic groups in the United Kingdom. We use the shorthand terms 'immigrants' and 'target ethnic minority groups' to refer to these two groups. The groups, of course, overlap, with some people belonging to both (e.g., first-generation Indians) and others belonging to only one or the other (e.g., UK-born of Pakistani ethnicity or Pakistani parents, first-generation Poles). To define immigrants, it was sufficient that they were born in a country other than the United Kingdom, regardless of the age at which they first came to the United Kingdom. To define target ethnic minorities, our starting point was the official Office for National Statistics ethnic group categories. However, in the screening questionnaire, we explicitly asked about 'mixed Indian,' who were allocated to the target Indian sample, and 'mixed Caribbean/West Indian,' who were allocated to the Black Caribbean sample. In addition, we screened in those with minority group origins other than those of the five groups who were living in the sampled areas (for screening question see Appendix 1, and McFall, Nandi, and Platt 2017)

\subsection{Sampling strategy}

There are several important decisions to be made about the parameters of a high-quality sample design with full population coverage and strict probability sampling. These decisions will affect the statistical efficiency of the sample, the cost efficiency, and the practical challenges in implementing the fieldwork. This section sets out the options, the information that can be used to evaluate them, and the implications of different decisions. In each subsection, a general discussion of the issues is followed by description of what was done in the case of the UKHLS-IEMB. 


\subsubsection{Full population coverage}

In the United Kingdom, as in many countries, immigrant and ethnic minority subpopulations are heavily geographically skewed. There are some areas where they constitute a large proportion of the total population and others where they are hardly represented at all. This presents a major challenge as the cost per recruited sample member of face-to-face screening can vary between areas by an order of magnitude. Screening the same proportion of addresses in all (types of) areas would be prohibitively expensive. For example, if $5 \%$ of households belong to the subpopulation of interest and if the screening exercise could be expected to achieve a $60 \%$ response rate, then to obtain a sample of 3,000 households it would be necessary to attempt screen interviews with 100,000 households. In a design that encompasses a range of subpopulations of interest (e.g., specific ethnic groups) the undertaking becomes substantially more complicated. And if all areas were to be screened the screening sample would have to be even larger. To avoid such a prohibitively large screening exercise, the main options are to either sample the low-density areas at a (much) lower rate than the high-density areas or to rely on an existing survey to supply the sample in the low-density areas. The existence of a survey with full population coverage on which to piggyback in this way greatly increases the feasibility of obtaining a full-coverage sample. However, the size of the available sample of the subpopulation of interest may be modest and this will affect the statistical efficiency of the sample (see Section 3.3.4 below). To obtain a large enough overall sample of each subpopulation of interest, the sample taken from an existing survey must be 'boosted' with samples selected from areas where the subpopulations are a relatively sizeable proportion of the total. In this way, the overall analysis sample will have two parts, the minority component of a general population sample, which will provide full coverage but modest sample sizes, and the boost samples, which can be designed to provide good sample sizes but will have more restricted coverage.

The UKHLS-IEMS relies on the main UKHLS sample to provide complete population coverage of both immigrants and ethnic minorities, supplemented by the boost samples described in the next section. In fact, the population coverage of the main sample is not quite complete: the longitudinal nature of the survey means that immigrants living in households where every household member entered the United Kingdom since the time of wave 1 of the survey (2009-2010) are excluded. Such recent immigrants will be included only in the IEMB. 


\subsubsection{Coverage of the boost samples}

Boost samples to augment a modest-sized full-coverage sample must be restricted to the densest part of the overall population. A key design decision is how to divide the population into 'dense' and 'less dense.' If a relatively extreme definition of 'dense' is adopted, fieldwork will be more cost-effective, so a larger sample size can be achieved for any given budget, but the overall sample will suffer from statistical inefficiency (see Section 3.3.4). A broader definition of 'dense' will result in a smaller, but more statistically efficient, sample. An appropriate compromise would be one which aims to maximise the precision of survey estimates - a factor which is determined by the combination of sample size and statistical efficiency. It is inevitable - and appropriate that the adopted definition should depend on the cost implications of alternatives.

For the IEMB, the 'less dense' population stratum, from which no boost sample would be selected, was defined as areas in which less than $10 \%$ of persons were 'ethnic minorities' (using the definition outlined above) and less than 12\% were born outside the United Kingdom ('immigrants'). The geographical areas to which this definition was applied were Government Statistical System Lower Super Output Areas (LSOAs) in England and Wales and Scottish Data Zones (SDZs) in Scotland. LSOAs and SDZs are contiguous areas containing an average of around 1,500 residents and are used for the collection and publication of a wide range of government statistics. Publiclyavailable data ${ }^{3}$ from the 2011 United Kingdom Population Census at LSOA and SDZ level on ethnic group and country of birth was used to define the sampling strata. According to 2011 Census data, the 'dense' stratum from which the boost sample would be selected provided coverage of between $84 \%$ (Indians) and $91 \%$ (Pakistanis) of the target ethnic groups, and $74 \%$ of persons born outside the United Kingdom, while $65.1 \%$ of all persons (and $66.4 \%$ of all UK households) resided in the 'less dense' stratum (see the final column in the second panel of Table 1). This gives an indication of the cost efficiency of the design, as fieldwork could be restricted to just one-third of the territory, while still covering a high proportion of each of the subpopulations of interest.

\subsubsection{Sampling strata and sampling fractions}

Within the 'dense' stratum, a boost sample can be designed in a way which is more or less heavily (or not at all) skewed towards the denser areas. The more it is skewed, the lower the unit cost of data collection and hence, the larger the sample size that can be

${ }^{3}$ Sources: http://www.nomisweb.co.uk/census/2011 for England and Wales; http://www.scotlandscensus. gov.uk/ods-web/data-warehouse.html for Scotland. 
achieved within a given budget. However, a more skewed sample implies a loss of statistical efficiency, i.e., larger standard errors for any given sample size. Thus, the challenge is to identify a design which minimises standard errors for a given budget. This involves a trade-off between the effects of sample size and those of statistical efficiency. The effect of sample design on standard errors will vary between survey estimates (Kaminska and Lynn 2017), but a practical approximation to the effect can be obtained by assuming that the variance of an estimate will be unrelated to selection probabilities in any given design. This can in some sense be thought of as an average or typical design effect, and is the approach used to inform sample design by many major surveys, for example the European Social Survey (Lynn et al. 2007).

For the UKHLS-IEMS, design effects for each of the six target populations of interest (five target ethnic minorities, plus immigrants), and field costs, were estimated for several alternative designs, each involving three or four sampling strata with sampling fractions that are higher in the denser strata. The strata chosen for the final design are detailed in Table 1 (top panel). It proved necessary to first create a stratum containing relatively high concentrations of Black Africans. This was necessary because the ratio of desired sample size to population size was higher for Black Africans than for any of the other target groups and because this group is less concentrated geographically than the other target ethnic minority groups. A second stratum consisted of all other areas with a relatively high concentration of UK-born (target) ethnic minorities, while a third stratum contained areas with high concentrations of immigrants who were not from the target ethnic minority groups. It was necessary to separate out such areas as the requirement to oversample immigrants would otherwise have led to an inefficiently large proportion of the ethnic minority sample being immigrants (and of the immigrant sample being ethnic minorities). A fourth stratum consisted of all other areas with high concentrations of either ethnic minorities (regardless of whether or not they were UK-born) or immigrants (regardless of whether or not they were ethnic minorities). All other areas were consigned to a fifth stratum from which no selections would be made for the boost sample. Stratum 5 in Table 1 is therefore the 'less dense' stratum referred to in Section 3.3.2 above. 
Table 1: $\quad$ Sampling strata: Definition, population distribution, sampling fractions

\begin{tabular}{lcllll}
\hline Definition & Stratum 1 & Stratum 2 & Stratum 3 & Stratum 4 & Stratum 5 \\
\hline Black Africans & $20 \%+$ & $<20 \%$ & $<20 \%$ & $<20 \%$ & $<20 \%$ \\
EM5 born in United Kingdom & Any & $10 \%+$ & $10 \%+$ & $<10 \%$ & $<10 \%$ \\
Non-EM5 immigrants & Any & $<10 \%$ & $10 \%+$ & Any & Any \\
EM5 persons & Any & Any & Any & $10 \%+$ & $<10 \%$ \\
Immigrants & Any & Any & Any & or $12 \%+$ & $<12 \%$ \\
\hline Population (row percentages) & & & & & \\
Indian & 1.1 & 11.2 & 48.5 & 23.5 & 15.7 \\
Pakistani & 1.0 & 22.0 & 54.6 & 13.4 & 9.1 \\
Bangladeshi & 3.2 & 12.1 & 58.7 & 15.8 & 10.3 \\
Black African & 14.6 & 1.7 & 46.3 & 25.1 & 12.3 \\
Black Caribbean & 7.9 & 3.8 & 55.7 & 19.6 & 13.1 \\
Non-United Kingdom & 3.4 & 3.8 & 34.8 & 32.1 & 25.9 \\
Total persons & 1.0 & 2.4 & 11.9 & 19.5 & 65.1 \\
Population LSOAs & 328 & 821 & 3,808 & 6.557 & 23,239 \\
\hline Sample design & & & & & \\
Sample LSOAs & 57 & 36 & 111 & 46 & 0 \\
Fraction of LSOAs (A) & 0.174 & 0.044 & 0.029 & 0.007 & - \\
Fraction of households (B) & 0.053 & 0.173 & 0.080 & 0.167 & - \\
Overall sampling fraction (A × B) & 0.0093 & 0.0076 & 0.0023 & 0.0012 & - \\
\hline
\end{tabular}

The uneven distribution over the strata of the population in the target groups is apparent in the middle panel of Table 1. For example, it can be seen that stratum 1, while containing only $1 \%$ of the total population, contains $14.6 \%$ of Black Africans. The extent to which different ethnic groups co-reside in the same areas can also be seen, as stratum 1 also contains $7.9 \%$ of Black Caribbeans. This tendency for co-residence is a factor which makes it hard to develop an area-based sample design that will deliver equal numbers in each of several population subgroups: it is hard to find areas that would boost the numbers of one ethnic minority group without simultaneously boosting other ethnic minority groups. It would in any case be undesirable to concentrate the sample of one group in such unusual areas that contain few members of other groups.

To achieve adequate sample sizes in each target group while also keeping the total number of screened addresses within budget constraints, it was necessary to vary substantially the sampling fractions over the four included strata. As can be seen in the final row of Table 1, the sampling fraction in stratum 1 was almost eight times that in stratum 4. This variation in selection probabilities reduces the precision of survey estimates (see Section 3.3.4 below) but does not introduce bias, provided that estimates are based on weighted data in which each person or household is weighted in inverse proportion to the probability with which they were selected. In setting the sampling fractions, the effect on precision was taken into account: it would have been possible to 
achieve the same number of interviews at lower cost (fewer addresses screened) but this would have involved a much larger range of sampling fractions and hence an unacceptable loss of precision.

Figure 1 shows the number of persons expected to be enumerated in responding households in each of the six target groups, broken down by sampling stratum. The different contributions of the strata are clear. Stratum 1 was expected to be the main source of persons of Black African origin. Stratum 2 mainly contributes persons of Indian and Pakistani origin. Stratum 3 contributes substantially to all groups, but is the largest source of persons of Black Caribbean origin, while stratum 4 mainly provides foreign-born persons who are not members of any of the target ethnic minorities.

\section{Figure 1: Contribution of sampling strata to target sample sizes (estimated} number of enumerated persons)

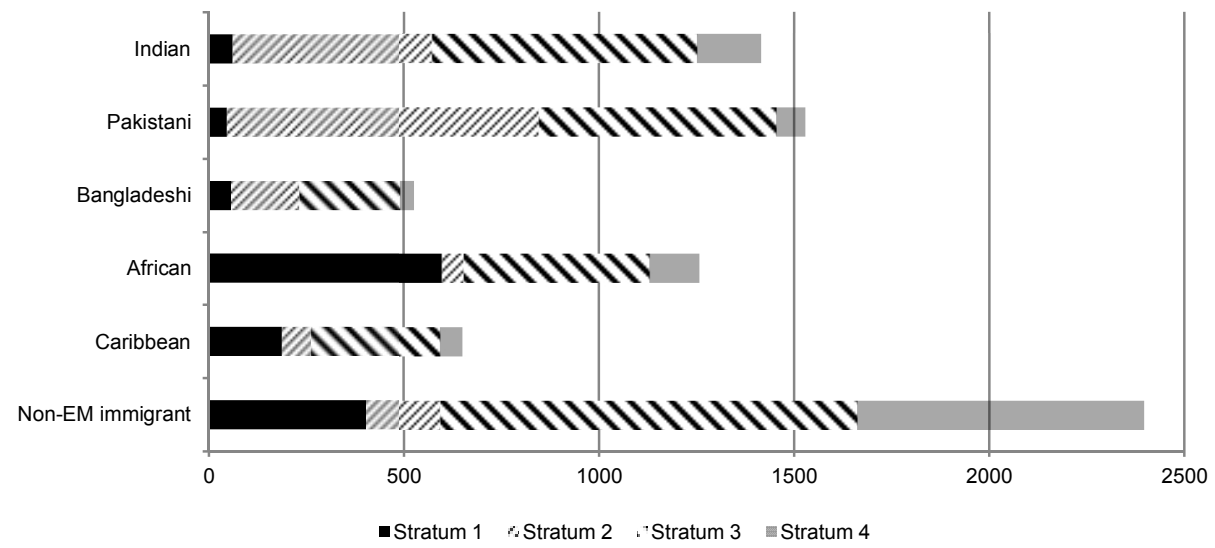

\subsubsection{Overall statistical efficiency}

The precision of survey estimates will generally be lower the greater the variation in selection probabilities, and hence in design weights. The reduction in precision caused by variation in design weights is referred to as the 'design effect.'

To approximate the distribution of design weights we must remember that the IEMB is designed to be analysed in combination with the existing UKHLS sample, which has full population coverage (apart from recent immigrant households) and which itself consists of a general population sample (GPS) and an ethnic minority boost 
(EMB) that were selected at the start of the survey in 2009-2010, plus the preexisting British Household Panel Survey (BHPS) sample. Therefore, each eligible person has up to four routes through which they could have been included in the survey. They could have been selected into the BHPS, GPS, EMB, or IEMB. The selection probability of an eligible person, $P\left(I E M S_{i}\right)$, is therefore the sum of the probabilities of being included in each of these four samples (some, but not all, of which could be zero):

$$
P\left(I E M S_{i}\right)=P\left(\text { BHPS }_{i}\right)+P\left(G P S_{i}\right)+P\left(E M B_{i}\right)+P\left(I E M B_{i}\right) .
$$

$P\left(G P S_{i}\right)$ is approximately 0.00167 for all eligible persons (as 47,520 postal addresses were selected with equal probabilities out of approximately $28,520,000$ addresses in GB). $P\left(B H P S_{i}\right)$ depends on whether person $i$ lived in England, Wales, or Scotland at the time original BHPS sample was selected in 1991, in Wales or Scotland when boost samples were selected in 1999, or in Northern Ireland when the Northern Ireland sample was selected in 2001. $P\left(I E M B_{i}\right)$ depends on the sampling strata of residence in 2015 and corresponds to the sampling fractions in the final row of Table 1. $P\left(E M B_{i}\right)$ is more complicated, and depends on the combination of ethnic group and postal sector of residence in 2009-2010. The selection probability for the sample into which a person was selected is known from the sample design. The probability for samples selected subsequently can be estimated using the survey data. But to establish selection probabilities for earlier samples, additional questions were included in the household grid at the first wave of data collection for each new sample. For example, each member of IEMB was asked where they resided in 2009, in order to establish $P\left(E M B_{i}\right)$.

In Table 2 we show the variance inflation factor (design effect) for several key analysis groups. In each case these factors are considerable, reflecting the wide range of selection probabilities that necessarily result from a sample design that attempts to balance competing objectives. The upper panel shows the extent of variance inflation that arises solely from variability in selection probabilities within the IEMB; the lower panel shows the overall extent of variance inflation when analysing the combined UKHLS-IEMS. Statistical efficiency in the IEMB is lowest for the Black Caribbean and Black African groups. This stems from the fact that these groups are well represented in all four of the sampled strata (Table 1). Consequently, the samples in these groups contain a wide range of selection probabilities. Across the whole UKHLS-IEMS, statistical efficiency is lowest for persons born outside the United Kingdom (design effect of 2.80), but as the sample size is large, the effective sample remains large too $(2,880)$. Efficiency is much higher for post-2009 immigrants (design effect of 1.30), as these could only be selected through the IEMB. However, the effective sample size for analysis of this group is smaller, at 656 . We return to achieved sample sizes in 
Section 6, but these design effects should be borne in mind when considering the numbers available for analysis.

Table 2: Design effects for key analysis subgroups

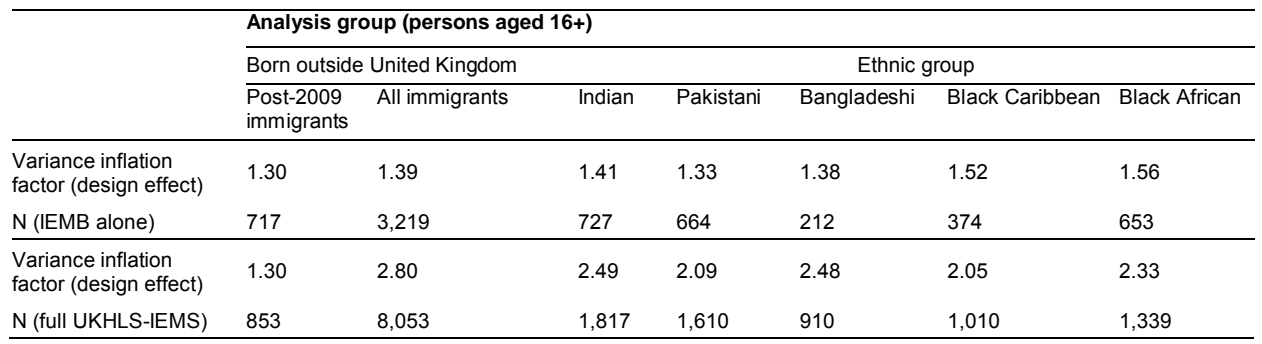

\section{Implementing the immigrant and ethnic minority survey}

\subsection{Screening and interviewing}

The two-stage contact process where households were first screened for eligibility and subsequently, if eligible, interviewed required a short screening instrument as well as the main substantive questionnaire. An important decision was the choice of data collection mode for each of these stages. Options could have included face-to-face interviewing, telephone interviewing, paper self-completion, and online selfcompletion. These modes differ greatly in field costs, likely response rates, and data quality (de Leeuw 2005). The success of the screening stage was fundamental to the statistical quality of the longitudinal study for years to come. Given that, it was decided that this stage must be implemented face-to-face, as this was the mode likely to maximise cooperation rates. As an interviewer visit was necessary to carry out the screening, it was efficient to also conduct the initial interviews face-to-face. However, once the sample was identified and recruited, there was no reason not to consider other modes for future waves of data collection.

The screening questionnaire consisted of two questions. The first was designed to identify migrants, while the second asked about ethnic minority background. If the respondent answered 'yes' to either question, the household was deemed eligible. The screening questionnaire - reproduced in Appendix 1 - was administered using a card presented to respondents on the doorstep, which listed relevant answer categories. The card was only available in English, although a translation card was used in households where none of the members spoke English to identify the language spoken so that a 
bilingual interviewer or an agency translator could be sent to the address to conduct screening and interviewing.

The main questionnaire needed to meet two main aims. First, it had to allow sufficient comparability with the existing UKHLS sample to facilitate incorporation into the main sample and analysis across the whole survey population. Second, to facilitate relevant migration research it also had to include migration- and minorityspecific measures to take debates forward. The latter is also likely to provide greater engagement with the sample as it relates more closely to their salient experiences. At the same time, funding and considerations of respondent burden required that it be kept relatively short. Like the main stage questionnaire, as well as an individual (30 minute) interview it also comprised a household grid, and a household questionnaire, asked just of one household member. A proxy interview allowed information to be collected about absent households members. A summary of the individual questionnaire modules is given in Appendix 2. While it included key areas of relevance to immigrants and to migration research, the majority of the questionnaire was relatively generic. This potentially raised challenges for engagement and retention of participants, and indicated that particular effort would need to be put into the fieldwork to ensure sufficient response and engagement.

\subsection{Fieldwork procedures}

Obtaining cooperation with probability-based face-to-face surveys is challenging. The trend in recent years - in almost all developed countries - has been for survey response rates to decline and for increasing resources being needed to maintain response rates (de Leeuw and de Heer 2002; Brick and Williams 2013). Furthermore, immigrants and ethnic minorities tend to be amongst the population subgroups least likely to participate in surveys (Font and Mendez 2013). In that context it was clear from the outset that successfully making contact with a large proportion of the sampled households and obtaining their cooperation with both the screen and the main interview would require a thorough and careful approach to the design and implementation of all aspects of field procedures.

First, for inclusion and accuracy of response, but also for engagement, we translated the instrument and related materials. On the basis of information from the 2011 Census both on the first language of the most prevalent groups and their average level of fluency in English the decision was taken to translate the questionnaire into the following languages: Gujarati, Punjabi (Urdu), Punjabi (Gurmukhi), Bengali, Polish, Portuguese, Somali, Turkish, and Urdu. A language card allowed respondents who did not speak English to identify their language and a bilingual interviewer or interviewer 
accompanied by a professional translator to be allocated accordingly. For languages other than these nine, other household members, neighbours, and friends were used to assist in translation where necessary.

Second, to help ensure the screening interviewer was expected, the sampled households were sent a card in advance explaining the study and letting them know that an interviewer would be visiting. The card also informed the sample members about the possibility of being interviewed in other languages, if requested.

Third, steps were taken at the screening and interviewing stages to obtain the maximum response. Initially, the screening was carried out by the same interviewer who would conduct the interviews. This was to enable an immediate interview to be carried out following identification of eligibility, if the respondent was willing, rather than necessitating a second visit to carry out the interview. This also ensured that, given the focus on using the most qualified interviewers, it was skilled interviewers who were conducting the screening and attempting to establish eligibility. The disadvantage of this approach was that it had the potential to slow down the fieldwork and occupy much of the time of the skilled interviewers knocking on the doors of ineligible households. The large number of screening visits required to identify each eligible household is bound to have some impact on interviewer morale. As a result, six months into the fieldwork a split team of screeners and interviewers was first tested and then deployed across the study, with the interviewers recontacting eligible households after they had been screened in. The testing of this approach showed that noncontact rates were no higher, and it enabled interviewers to spend more time making repeat visits and maximising responses.

Fourth, a number of materials were produced and made available to the interviewers in order to help engage the new sample members. These included an information leaflet explaining the purpose of the study and a laminated page listing newspaper headlines drawing on recent findings from UKHLS to demonstrate impact. The information leaflet was often left behind in households that were screened in but where the interviews did not take place immediately. This gave household members an opportunity to familiarise themselves with the study and their involvement in it and gave the interviewer an excuse to revisit more reluctant households in order to answer any queries they might have as a result of reading the leaflet.

It is widely accepted that some form of monetary recognition is important both for participation and for subsequent panel maintenance (Laurie and Lynn 2009; Singer 2002). As for the main survey, after each achieved interview, the interviewer gave the respondent a $£ 10$ gift card.

Finally, all fieldwork procedures including translations were piloted and, after commencement of the fieldwork, response rates were closely monitored and changes implemented in fieldwork procedures as needed. Examples of changes made subsequent 
to piloting include shortening the questionnaire, updating the wording of the screening questions to include reference to children, and communicating expected screening rates to interviewers in their individual areas.

Detailed fieldwork progress reports, updated daily, revealed that by about halfway through the fieldwork response rates achieved were lower than expected. A number of steps were then taken with the aim of increasing response. These included briefing additional supervisors to support less experienced interviewers, conducting telephone conferences with interviewers in order to elicit and address any difficulties in the field, and introducing a weekly milestone calendar to remind interviewers and regional managers of deadlines for coverage targets. In addition, fieldwork on the first twoquarters of the sample was extended by two weeks to increase the number of interviews achieved through reissues, and a bonus fee was introduced to reissue interviewers for achieving productive interviews. Additional actions aimed at increasing household and within-household response included better monitoring of call record patterns to ensure that an optimum distribution of call attempts was made before accepting a 'noncontact' outcome to the screen or main interviews. Partial households (where some individuals have responded but others have not) were specifically targeted. Tailored personalised letters were sent to nonresponders in partial households emphasising the importance of all household members taking part. And towards the end of fieldwork unproductive individuals in otherwise productive households were also offered interviews by telephone.

\section{Results}

\subsection{Household response}

On the basis of the sample design described above, a total of 19,459 addresses were issued to be screened for the IEMB. Of those, $18.25 \%(3,552)$ were never screened. Reasons for failure to screen comprised noncontact in just over half of the cases $(1,854$ households, or $9.5 \%$ of the total issued sample), refusal in $28 \%$ (982) of nonscreened, and other reasons, including some with language difficulties for the remaining $20 \%$ of nonscreened (716 households). This means that of all those issued for screening 5\% refused at the point of screening, though some of the noncontacts could well have been refusals if contact had been possible.

Just over half of the issued sample, 10,307 (53\%) were screened and deemed ineligible, amounting to $65 \%$ of all those with a known screening outcome. This left 5,600 (35\% of all screened) households eligible for interview. Of these, 2,922 (52.2\%) provided a productive response (i.e., at least a household grid was completed); and in 
1,783 of these ( $28.8 \%$ of eligible households) all adults provided an interview. While the household response rate of $52 \%$ is relatively good for a general purpose survey among a population with typically much lower response rates, the estimate of the response rate at $52 \%$ does not take account of the fact that a share of those who could not be contacted for screening would also have been eligible. Among unproductive households there were 1,792 (32\%) refusals and $705(12.6 \%)$ noncontacts.

Overall, this illustrates the ratio of issued households needed to ensure participating households, even with a carefully targeted design: nearly 7 to 1 .

\subsection{Individual response}

A total of 8,517 individuals (including children) were living in the 2,922 responding households; and on average, there were 2.15 adults (aged 16 or older) per household, leading to 6,260 adults eligible for a full adult interview. Of these, 4,458 (71\%) gave a full interview and 198 (3.2\%) proxy interviews (total 4,656).

This gives an individual response rate of $71 \%$ ( $74 \%$ including proxies). Table 3 shows that these response rates are somewhat lower than for the other samples comprising the UKHLS at its first wave - even slightly lower than the wave one ethnic minority boost. At the same time, the IEMB was taking place six years later in a context of steadily declining response rates; and with a reasonable level of household response, particularly for an immigrant and ethnic minority population, the response rates demonstrate the payoff from the effort put into achieving a high-quality, highresponding sample.

Table 3: Comparing wave 1 individual response rates across different Understanding Society samples

\begin{tabular}{lcccc}
\hline & \multicolumn{2}{c}{ Wave 6 } & \multicolumn{3}{c}{ Wave 1 } \\
\cline { 2 - 5 } & IEMB & GPS GB & GPS NI & EMB \\
\hline Only full interviews & $71.2 \%$ & $82.0 \%$ & $77.3 \%$ & $72.4 \%$ \\
Proxy interviews & $3.2 \%$ & $5.3 \%$ & $3.5 \%$ & $6.9 \%$ \\
\hline
\end{tabular}

Note: Individual adult response rates are defined among those who were eligible for individual adult interviews: 16+-year-olds enumerated in responding households. 


\section{Sample description}

So how did the achieved sample map on the expectations in terms of composition and sample sizes, and how does it compare with the characteristics of the different populations as known from the 2011 Census?

\subsection{Target and achieved samples}

Table 4 illustrates how far the expectations of the sample design and assumptions, based on the best existing information on household distributions and characteristics and likely response rates, were met in the achieved sample. Overall the achieved number of households was slightly lower than that targeted. But the number of enumerated individuals was substantially lower, since household sizes, at least among responding households, were lower than predicted. This also had knock-on effects on the number of adult respondents, alongside the slightly lower response rates. We can also see that despite constructing the strata to avoid excessive overlap between ethnic minorities and immigrants in the sample, there were still more ethnic minority immigrants and fewer other immigrant households sampled than targeted. This may relate to the relative stability of the populations in the sampled areas since the 2011 Census. Indeed the total number of immigrant households exceeded the target, even though nearly two-thirds were from the target ethnic minority groups. This again has knock-on effects on the numbers of adult respondents who were not from the ethnic minority groups; though the smaller household sizes meant there were not as many ethnic minority adult respondents as the household enumeration might have implied.

The overall sample provides large numbers for analysis on a number of dimensions. However, as noted in Section 3, the effective sample sizes are not the same as the absolute sample sizes. Table 4 therefore additionally provides the effective sample sizes for adults from the six target groups (immigrants and five target ethnic minority groups). These show the 'costs' of the design in terms of statistical efficiency. Nevertheless, the IEMB still delivered substantial effective sample sizes: even the smallest, Bangladeshi, target group delivers an effective sample size of 150 . 
Lynn et al.: Design and implementation of a high-quality probability sample of immigrants

Table 4: $\quad$ Target and achieved sample numbers in the IEMB

\begin{tabular}{|c|c|c|c|c|c|c|c|}
\hline & \multicolumn{2}{|c|}{$\begin{array}{l}\text { Enumerated } \\
\text { households with at } \\
\text { least one enumerated } \\
\text { person who is }\end{array}$} & \multicolumn{2}{|c|}{$\begin{array}{l}\text { Enumerated persons } \\
\text { who are }\end{array}$} & \multicolumn{3}{|c|}{ Adult respondents who are } \\
\hline & Target & Actual $^{1}$ & Target & Actual $^{1}$ & Target & Actual $^{3}$ & $\begin{array}{l}\text { Effective } \\
\text { sample size }\end{array}$ \\
\hline Immigrant & 1,900 & 2,416 & 4,800 & 4,547 & 3,412 & 3,219 & 2,317 \\
\hline Immigrant, target ethnic group & 800 & 1,394 & 2,400 & 2,549 & 1,706 & 1,776 & \\
\hline Immigrant, others & 1,100 & 1,022 & 2,400 & 1,998 & 1,706 & 1,443 & \\
\hline $\begin{array}{l}\text { Country of birth information } \\
\text { missing }\end{array}$ & & 21 & & 94 & & 0 & \\
\hline Born in United Kingdom & & 485 & & 3,876 & & 1,437 & \\
\hline Total & 2,960 & 2,922 & 8,550 & 8,517 & 5,106 & 4,656 & \\
\hline $\begin{array}{l}\text { All ethnic minorities (included in } \\
\text { screen question) }\end{array}$ & 1,860 & $2,203^{2}$ & 6,150 & 6,269 & 3,400 & 3,333 & \\
\hline Indian & 430 & 440 & 1,500 & 1,260 & 915 & 727 & 507 \\
\hline Pakistani & 370 & 377 & 1,500 & 1,454 & 750 & 664 & 498 \\
\hline Bangladeshi & 120 & 126 & 500 & 405 & 280 & 212 & 153 \\
\hline Black Caribbean & 290 & 323 & 650 & 573 & 370 & 374 & 246 \\
\hline Black African & 400 & 494 & 1,250 & 1,229 & 650 & 653 & 418 \\
\hline Others & 250 & 651 & 750 & 1,348 & 435 & 703 & \\
\hline $\begin{array}{l}\text { Other ethnic group (not included } \\
\text { in screen question) })^{4}\end{array}$ & & 697 & & 2,158 & & 1,321 & \\
\hline Ethnic group information missing & & 22 & & 90 & & 2 & \\
\hline Total & 2,960 & 2,922 & 8,550 & 8,517 & 5,106 & 4,656 & \\
\hline
\end{tabular}

Notes: ${ }^{1}$ Based on the country-of-birth question asked in the household grid and the ethnic-group question asked in the household grid.

As there may be households with enumerated individuals of more than one of the screened-in ethnic minority groups, the total number of households with at least one screened-in ethnic minority enumerated person is 2,203 while the total number of households with at least one Indian, Pakistani, Bangladeshi, Black Caribbean, Black African, or any of the other non-targeted screened-in ethnic groups adds up to 2,411 .

${ }^{3}$ Includes proxy, based on the self-reported country-of-birth question and the self-reported ethnic-group question. If these were missing, the country-of-birth question and the ethnic-group question asked in the household grid was used to impute these.

${ }^{4}$ These are primarily white-majority household members.

The purpose of IEMB was to boost the sample numbers for immigrants and ethnic minorities to facilitate research questions relating to generation, cohort, and specific subgroups (countries of origin) of interest, as well as topics of interest across these groups. In Table 5 we therefore provide the sample sizes of immigrants from some key groups of countries and, in Table 6 those of the five target ethnic minority groups by generation (whether born in United Kingdom or not) in the IEMB. The tables show the IEMB amplifies the existing coverage of minorities and immigrants to provide substantial samples for analysis of variation across national, ethnic, and regional origins and of generational change. 
Table 5: Number of adult respondents in wave 6 by countries of birth across the different samples

\begin{tabular}{|c|c|c|c|}
\hline & UKHLS without IEMB & IEMB & Total: UKHLS-IEMS \\
\hline \multicolumn{4}{|l|}{ Country of birth } \\
\hline Africa & 962 & 693 & 1,655 \\
\hline Caribbean Islands & 271 & 150 & 421 \\
\hline South Asia ${ }^{1}$ & 1,817 & 1,050 & 2,867 \\
\hline South East and East Asia $^{2}$ & 310 & 158 & 468 \\
\hline Eastern Europe (excluding non-EEA) ${ }^{3}$ & 279 & 434 & 713 \\
\hline Western Europe (excluding non-EEA) ${ }^{4}$ & 598 & 359 & 957 \\
\hline English-speaking countries ${ }^{5}$ & 201 & 69 & 270 \\
\hline Middle East & 160 & 142 & 302 \\
\hline Central and South America & 67 & 66 & 133 \\
\hline Other & 162 & 97 & 259 \\
\hline All immigrants & 4,834 & 3,219 & 8,053 \\
\hline Arrived in or before 2009 & 4,659 & 2,482 & 7,141 \\
\hline Arrived after 2009 & 136 & 717 & 853 \\
\hline Arrival date missing & 39 & 20 & 59 \\
\hline
\end{tabular}

Notes: ${ }^{1}$ Born in Afghanistan, Bangladesh, Bhutan, Maldives, Nepal, Pakistan, India, or Sri Lanka.

${ }^{2}$ Born in Brunei, Cambodia, China, East Timor, Hong Kong, Indonesia, Japan, Laos, Macao, Malaysia, Mongolia, Myanmar, Philippines, Singapore, Taiwan, Thailand, Vietnam, North Korea, or South Korea.

${ }^{3}$ Poland, Bulgaria, the Czech Republic, Estonia, Hungary, Latvia, Lithuania, Romania, or Slovakia.

${ }^{4}$ Ireland, France, Germany, Italy, Spain, Cyprus, Austria, Belgium, Denmark, Finland, Greece, Iceland, Malta, Norway, Portugal, Sweden, or the Netherlands.

${ }^{5}$ Australia, Canada, New Zealand, or the United States.

Table 6: Number of adult respondents in wave 6 by ethnic group across the different samples

\begin{tabular}{|c|c|c|c|}
\hline & UKHLS without IEMB & IEMB & Total: UKHLS-IEMS \\
\hline Indian & 1,090 & 727 & 1,817 \\
\hline Born in United Kingdom & 375 & 237 & 612 \\
\hline Not born in United Kingdom & 714 & 490 & 1,204 \\
\hline Pakistani & 946 & 664 & 1,610 \\
\hline Born in United Kingdom & 403 & 243 & 646 \\
\hline Not born in United Kingdom & 543 & 421 & 964 \\
\hline Bangladeshi & 698 & 212 & 910 \\
\hline Born in United Kingdom & 277 & 65 & 342 \\
\hline Not born in United Kingdom & 421 & 147 & 568 \\
\hline Black Caribbean & 636 & 374 & 1,010 \\
\hline Born in United Kingdom & 361 & 204 & 565 \\
\hline Not born in United Kingdom & 274 & 170 & 444 \\
\hline Black African & 686 & 653 & 1,339 \\
\hline Born in United Kingdom & 125 & 105 & 230 \\
\hline Not born in United Kingdom & 560 & 548 & 1,108 \\
\hline Others (included in screen question) & 1,284 & 703 & 1,987 \\
\hline Born in United Kingdom & 532 & 195 & 727 \\
\hline Not born in United Kingdom & 751 & 508 & 1,259 \\
\hline All ethnic minorities & 5,340 & 3,333 & 8,673 \\
\hline Born in United Kingdom & 2,073 & 1,049 & 3,122 \\
\hline Not born in United Kingdom & 3,263 & 2,284 & 5,547 \\
\hline
\end{tabular}




\subsection{Quality of coverage of the Understanding Society sample in wave $6(2014 / 15)$}

Even if the sample sizes are large and we know them to cover a diverse range of areas, there remains the question of the extent to which the IEMB helped to deliver a highquality sample in terms of distributions of immigrants and ethnic minority groups across key demographics to ensure its utility for researchers to exploit for diverse research purposes. In final deposited data, sample weights aim to match the UKHLSIEMS to population distributions, to ensure the study is representative. Here, by contrast we focus on the raw distributions from the five target ethnic minority groups and immigrants in the UKHLS-IEMS at wave 6 to identify the extent to which it demonstrates good quality of coverage across key dimensions by comparison with the 2011 Census. We include the weighted distributions, which are in practice very similar to the unweighted ones shown, in the Appendix (Tables A1-A3). Even if the UKHLSIEMS were completely representative, we would not expect the distributions to be identical because they are conducted at different dates: the UKHLS-IEMS includes those who arrived after 2011, and excludes those who left or died after this date, while those who were present in 2011 have aged since.

We find that the sex composition of the different ethnic groups in the UKHLSIEMS is similar to the 2011 population (See Table 7), though the UKHLS-IEMS includes a slightly smaller proportion of men, particularly Black Caribbean men than in the census. When looking at the age distribution, the UKHLS-IEMS is also highly comparable to the 2011 Census, though the UKHLS-IEMS shows a slightly higher proportion of Indian and Black Caribbean children and lower proportion of Bangladeshi children.

Table 7: Sex and age composition within target ethnic and immigrant groups

\begin{tabular}{|c|c|c|c|c|c|c|c|c|}
\hline & \multicolumn{2}{|c|}{$\%$ Men (16+) } & \multicolumn{2}{|c|}{ Age $0-15, \%$} & \multicolumn{2}{|c|}{ Age $16-64, \%$} & \multicolumn{2}{|c|}{ Age $64+, \%$} \\
\hline & $\begin{array}{l}2011 \\
\text { Census }\end{array}$ & $\begin{array}{l}\text { UKHLS- } \\
\text { IEMS }\end{array}$ & $\begin{array}{l}2011 \\
\text { Census }\end{array}$ & $\begin{array}{l}\text { UKHLS- } \\
\text { IEMS }\end{array}$ & $\begin{array}{l}2011 \\
\text { Census }\end{array}$ & $\begin{array}{l}\text { UKHLS- } \\
\text { IEMS }\end{array}$ & $\begin{array}{l}2011 \\
\text { Census }\end{array}$ & $\begin{array}{l}\text { UKHLS- } \\
\text { IEMS }\end{array}$ \\
\hline Indian & 51 & 50 & 19 & 22 & 69 & 64 & 12 & 13 \\
\hline Pakistani & 51 & 49 & 33 & 35 & 61 & 59 & 6 & 6 \\
\hline Bangladeshi & 52 & 50 & 35 & 31 & 60 & 65 & 5 & 5 \\
\hline Black African & 48 & 46 & 30 & 32 & 66 & 63 & 4 & 5 \\
\hline Black Caribbean & 47 & 42 & 17 & 21 & 66 & 64 & 17 & 16 \\
\hline Immigrants $^{1}$ & 48 & 46 & 8 & 5 & 76 & 77 & 16 & 18 \\
\hline
\end{tabular}

Notes: ${ }^{1}$ As country-of-birth information was not collected about children aged 0-10, except in the IEMB, for the rest of the UKLHIEMS we estimate it by using parental time of arrival.

The census figures come from the England and Wales 2011 Census, as the censuses for Scotland and Northern Ireland employ different categories. The vast majority of immigrants and ethnic minorities in the United Kingdom live in England and Wales, making it an appropriate comparator. UKHLS-IEMS figures are unweighted percentages using information for all enumerated household members. As a census-type ethnic-group question was only asked of adult full respondents, for this table we used information from the self-reported ethnic group and country of birth as well as the information provided in the household grid and screen questionnaire for nonrespondents. The ethnicity and immigrant status was imputed for some children under 10 years old using information about their parents' ethnicity and the year their parents arrived in the United Kingdom. 
The changing profile of educational attainment is of interest across migration and ethnicity scholars from a wide range of disciplines. Having reliable information on qualifications is a potential generic strength of the study. Table 8 shows those from the target groups with degree level qualifications in the UKHLS-IEMS compared to the 2011 Census. It shows broadly comparable rates of adult respondents with degree or higher educational qualification across the two sources. Interestingly, if anything, the UKHLS-IEMS respondents seem slightly less well-qualified than the census population.

Table 8: Degree qualifications by ethnic group and immigrant status (16+-year-olds)

\begin{tabular}{lll}
\hline & Degree or higher $^{1}$ & \\
\hline Indian & 2011 Census, England \& Wales (\%) & UKHLS-IEMS (\%) \\
Pakistani & 42 & 40 \\
Bangladeshi & 25 & 25 \\
Black African & 20 & 22 \\
Black Caribbean & 40 & 35 \\
Immigrants & 26 & 21 \\
\hline
\end{tabular}

${ }^{1}$ This corresponds to 'level 4 or higher' in the census tables and 'degree' in the UKHLS data.

Finally, Table 9 compares patterns of economic activity. The UKHLS-IEMS is, again, broadly comparable with the 2011 Census, though with higher proportions of home-makers among the UKHLS-IEMS sample.

Table 9: Ethnic group by economic activity (16+-year-olds)

\begin{tabular}{|c|c|c|c|c|c|c|c|c|c|c|c|c|}
\hline & \multicolumn{2}{|c|}{ Employed (\%) } & \multicolumn{2}{|c|}{ Unemployed (\%) } & \multicolumn{2}{|c|}{ Retired (\%) } & \multicolumn{2}{|c|}{ Family (\%) } & \multicolumn{2}{|c|}{ Students (\%) } & \multicolumn{2}{|c|}{ Other (\%) } \\
\hline & $\begin{array}{l}2011 \\
\text { Census } \\
\end{array}$ & $\begin{array}{l}\text { UKHLS- } \\
\text { IEMS }\end{array}$ & $\begin{array}{l}2011 \\
\text { Census } \\
\end{array}$ & $\begin{array}{l}\text { UKHLS- } \\
\text { IEMS }\end{array}$ & $\begin{array}{l}2011 \\
\text { Census } \\
\end{array}$ & $\begin{array}{l}\text { UKHLS- } \\
\text { IEMS }\end{array}$ & $\begin{array}{l}2011 \\
\text { Census } \\
\end{array}$ & $\begin{array}{l}\text { UKHLS- } \\
\text { IEMS }\end{array}$ & $\begin{array}{l}2011 \\
\text { Census } \\
\end{array}$ & $\begin{array}{l}\text { UKHLS- } \\
\text { IEMS }\end{array}$ & $\begin{array}{l}2011 \\
\text { Census } \\
\end{array}$ & $\begin{array}{l}\text { UKHLS- } \\
\text { IEMS } \\
\end{array}$ \\
\hline Indian & 64 & 60 & 6 & 6 & 10 & 13 & 5 & 10 & 8 & 9 & 7 & 2 \\
\hline Pakistani & 47 & 43 & 8 & 10 & 6 & 6 & 15 & 23 & 11 & 12 & 13 & 6 \\
\hline Bangladeshi & 46 & 44 & 10 & 11 & 6 & 4 & 16 & 21 & 11 & 13 & 11 & 7 \\
\hline Black African & 57 & 56 & 13 & 11 & 3 & 6 & 5 & 7 & 5 & 17 & 17 & 3 \\
\hline $\begin{array}{l}\text { Black } \\
\text { Caribbean }\end{array}$ & 57 & 56 & 10 & 11 & 16 & 17 & 3 & 4 & 3 & 9 & 11 & 3 \\
\hline Immigrants & 60 & 55 & 6 & 7 & 13 & 15 & 7 & 12 & 8 & 7 & 6 & 4 \\
\hline
\end{tabular}

Overall, though there are some ways in which the IEMB boost to the UKHLS has not resulted in a fully representative sample, given the constraints of sample design, the combined UKHLS-IEMS nevertheless maps remarkably well onto our closest population estimates across key characteristics. While there are some small differences 
between the UKHLS-IEMS and the census, importantly, the UKHLS-IEMS is not a sample that is dominated by a specific age, economic status, educational level or pattern of migration. Instead the sample represents the full diversity of the population broadly as it is expected to appear in the population, enabling engagement with key questions of social, cultural and structural integration, through the multi-topic coverage of the overall survey and its tracking of respondents over time, as well as its inclusion of both immigrant and UK-born minorities.

Moreover, while the IEMB was not able to focus to a significant degree on minority related topics, it will pick up questions relating to minority experience (e.g., harassment, identity) as it enters the next waves of the study. In addition, some explicit immigration-content was fielded to the IEMB, which will enable specific migration questions to be addressed with the large, high-quality sample offered, and which will be rolled out to all immigrants in the UKHLS over time. One brief illustrative example of this potential is a new question on reasons for migration that was asked of all adult immigrants in the IEMB. Table 10 presents a simple breakdown of responses. These show, as expected, that women are more likely to migrate for family reasons rather than work reasons. However, a substantial percentage of men, 23\%, also migrate for family reasons. Conversely, more men have migrated for education, but a substantial proportion of women have also done so. And nearly one in ten immigrants coming to the United Kingdom state they do so because they want to live in another country.

Table 10: Reasons for migration among immigrants, by sex (IEMB sample only)

\begin{tabular}{lrrrr}
\hline & \multicolumn{2}{c}{ All } & Among men (\%) & Among women (\%) \\
\hline Work & $\%$ & 33 & 22 \\
Family & 615 & 27 & 23 & 47 \\
Education & 833 & 36 & 20 & 12 \\
Political reasons & 363 & 16 & 9 & 7 \\
Want to live in another country & 177 & 8 & 11 & 8 \\
Other & 213 & 9 & 5 & 5 \\
\hline Total & 106 & 6 & 1,043 & 1,263 \\
\hline
\end{tabular}

\section{Conclusions}

This paper has discussed the rationale and implementation of a two-stage sample of immigrants and ethnic minorities in the United Kingdom. It has described the benefits of the design for achieving a high-quality sample, including 'piggybacking' on an existing study to provide not only comparability with the majority population, but also 
coverage of immigrants and minorities (albeit in smaller numbers) who live in lowdensity areas and therefore are costly to 'boost.' Two-stage sampling enables not just the practical attainment of a probability sample, in the absence of registers. It also allows for the targeting of second-generation minorities and specific groups, which may be impossible even with register data. It therefore has unique potential to deliver a resource for researchers to exploit to tackle some of the pressing questions facing migration research in demography and across disciplines.

There are a number of challenges, however, to achieving such a high-quality immigrant and ethnic minority survey. The first is cost, and the trade-off between cost and coverage. The second is attaining response in a context of declining response rates in general and particularly low response across minority and immigrant populations. The third is being able to predict with accuracy the composition of areas for sampling, and the likely household size of targeted households.

We discussed approaches to addressing these challenges, as well as remaining limitations. At the design stage, we described how different strata that cover different proportions of the populations of interest can be identified on the basis of existing population (census) data. Different designs which estimate the trade-off between sampling efficiency and economic efficiency can be developed so that a design which achieves the best sample size and efficiency within the given funding envelope can be achieved. This can also take into account the estimated coverage of different groups of interest.

Even with a focus on areas with denser coverage of the target populations, there is, however, extensive screening, which is not only costly, but can also have implications for the effectiveness of interviews. Robust and appropriate fieldwork processes are therefore needed, which also allow for adaptation in line with real-time monitoring of progress. We highlighted how a move took place from combined screening and interviewing, which had appeared to suggest the best way to achieve high household response, to separate screening and interviewing, which speeded up fieldwork without apparent decline in response. Ensuring interviewers follow contact protocols is also important, and allowing some flexibility over timing of reissues allowed us to 'mop-up' more hard-to-reach cases. Even with such strong fieldwork procedures and close monitoring, achieving response remains challenging, particularly for a multi-topic study without obvious immediate interest for participants. Nevertheless, we demonstrated that it was possible to attain $50 \%$ household response, a level that is substantially higher than for minority populations in most general or specific surveys. Within households, over $70 \%$ of eligible adults responded, providing large numbers of immigrant-origin respondents from different national origins and across generations.

The process and monitoring of fieldwork and the subsequent analysis of response, revealed that some expectations from our sample were not fully met. We reached fewer 
immigrants who were not from one of the target ethnic minority groups than we had expected, and household size was substantially smaller on average than predicted, resulting in a smaller number of adult respondents than anticipated. Among noncontacts at the screening stage we were by definition ignorant of their eligibility. We therefore cannot accurately estimate nonresponse among eligible households. By contrast with nonrespondent individuals in participating households we do know something about their characteristics and context, which can give us insight into demographic context of immigrants and minorities.

Our sample was broadly reflective of the 2011 Census population for the target populations. While there were some differences, especially in relation to economic inactivity, our new boost sample, in combination with the other UKHLS samples, appeared to be capturing a set of subpopulations who mapped the range of experience of their group. While this does not eliminate concerns about potential bias that may be linked to nonresponse it gives some confidence in the reach of the sample, as well as its potential to address multiple research questions across the life course. This along with the multi-topic nature of the study, the dedicated content that does cover the specifics of migrant experience, the household context, and the longitudinal follow up, does indeed suggest that a high-quality approach based on probability sampling and population screening offers a promising way forward for migrant surveys that will have long-term utility and offer a resource that is adaptive to the rapidly developing field of migrant and ethnic minority studies. 


\section{References}

Beauchemin, C. and González-Ferrer, A. (2011). Sampling international migrants with origin-based snowballing method: New evidence on biases and limitations. Demographic Research 25(3): 103-134. doi:10.4054/DemRes.2011.25.3.

Berthoud, R., Fumagalli, L., Lynn, P., and Platt, L. (2009). Design of the 'Understanding Society' ethnic minority boost sample. Colchester: University of Essex (Understanding Society Working Paper Series: 2009-02).

Blangiardo, G. (2008). The centre sampling technique in surveys on foreign migrants: The balance of a multi-year experience. Geneva: United Nations Statistical Commission (Eurostat Working Paper 12 Joint UNECE/Eurostat Work Session on Migration Statistics).

Brick, J.M. and Williams, D. (2013). Explaining rising nonresponse rates in crosssectional surveys. The Annals of the American Academy of Political and Social Science 645: 36-59. doi:10.1177/0002716212456834.

Brücker, H., Rother, N., and Schupp, J. (2016). Die IAB-BAMF-SOEP-Befragung von Geflüchteten: Überblick und erste Ergebnisse. Berlin: Deutsches Institut für Wirtschaftsforschung DIW (Politikberatung kompakt, 116).

Buck, N. and McFall, S. (2012). Understanding society: Design overview. Longitudinal and Life Course Studies 3(1): 5-17.

Burton, J. and Lynn, P. (2005). Issues for the development of a longitudinal survey of refugees. Colchester: University of Essex (Report to the Home Office).

CILS4EU (2016). Children of immigrants longitudinal survey in four European countries. Mannheim: Mannheim University (Technical Report, Wave 1 2010/2011, v1.2.0).

Crul, M. and Schneider, J. (2010). Comparative integration context theory: Participation and belonging in new diverse European cities. Ethnic and Racial Studies 33(7): 1249-1268. doi:10.1080/01419871003624068.

de Leeuw, E.D. (2005). To mix or not to mix data collection modes in surveys. Journal of Official Statistics 21(2): 233-255.

de Leeuw, E.D. and de Heer, W. (2002). Trends in household survey nonresponse: A longitudinal and international perspective. In: Groves, R.M., Dillman, D.A., Eltinge, J.L., and Little, R.J.A. (eds.). Survey nonresponse. New York: Wiley: $41-54$. 
Diehl, C., Lubbers, M., Muehlau, P., and Platt, L. (2016). Starting out: New migrants' socio-cultural integration trajectories in four European destinations. Ethnicities 16(2): 157-179. doi:10.1177/1468796815616158.

Drinkwater, S. and Garapich, M. (2011). The TEMPO survey of recent Polish migrants in England and Wales. Swansea: Wales Institute of Social and Economic Research, Data and Methods (WISERED/WDR/004).

Duque, I., Ballano, C., and Pérez, C. (2013). The 2007 Spanish National Immigrant Survey (ENI): Sampling from the Padrón. In: Font, J. and Mendez, M. (eds.). Surveying ethnic minorities and immigrant populations: Methodological challenges and research strategies. Amsterdam: IMISCOE/Amsterdam University Press: 69-83.

Elliott, M.N., Finch, B.K., Klein, D., Ma, S., Phuong Do, D., Beckett, M.K., Orr, N., and Lurie, N. (2008). Sample designs for measuring the health of small racial/ethnic subgroups. Statistics in Medicine 27(20): 4016-4029. doi:10.1002/ $\operatorname{sim} .3244$.

Erens, B. (2013). Designing high quality surveys of ethnic minorities in the UK. In: Font, J. and Mendez, M. (eds.). Surveying ethnic minorities and immigrant populations: Methodological challenges and research strategies. Amsterdam: IMISCOE/Amsterdam University Press: 45-68.

European Union Fundamental Rights Agency (2009). European Union minorities and discrimination survey: Main results report. http://fra.europa.eu/en/publication/ 2012/european-union-minorities-and-discrimination-survey-main-results-report.

Font, J. and Mendez, M. (2013). Surveying ethnic minorities and immigrant populations: Methodological challenges and research strategies. Amsterdam: IMISCOE/Amsterdam University Press.

Gresser, A. and Schacht, D. (2015). SCIP survey: Methodological report. Konstanz: University of Konstanz. www.scip-info.org.

Hobcraft, J. and Sacker, A. (2012). Guest editorial: The origins of Understanding Society. Longitudinal and Life Course Studies 3(1): 1-4.

Hornstra, N.E., Groenewold, G., and Lessard-Phillips, L. (2012). The Turkish and Moroccan second generation and their comparison group peers in Amsterdam and Rotterdam: The integration of the European Second Generation Technical Report and Codebook. Amsterdam: Pallas Publications (TIES 2006-2007 - The Netherlands. DANS Data Guide 9). 
Hughes, A.O., Fenton, S., and Hine, C.E. (1995). Strategies for sampling black and ethnic populations. Journal of Public Health Medicine 17(3): 187-192. doi:10.1093/oxfordjournals.pubmed.a043091.

Kahan, D. and Al-Tamimi, A. (2009). Strategies for recruiting Middle EasternAmerican young adults for physical activity research: A case of snowballs and salaam. Journal of Immigrant and Minority Health 11(5): 380-390. doi:10.1007/ s10903-008-9117-7.

Kalton, G. and Anderson, D.W. (1986). Sampling rare populations. Journal of the Royal Statistical Society A 149(1): 65-82. doi:10.2307/2981886.

Kaminska, O. and Lynn, P. (2017). Survey-based cross-country comparisons where countries vary in sample design: Issues and solutions. Journal of Official Statistics 33(3): 781-799. doi:10.1515/jos-2017-0007.

Laurie, H. and Lynn, P. (2009). The use of respondent incentives in longitudinal surveys. In: Lynn, P. (ed.). Methodology of longitudinal surveys. Chichester: Wiley: 205-233. doi:10.1002/9780470743874.ch12.

Luthra, R. and Platt, L. (2016). Elite or middling? International students and migrant diversification. Ethnicities 16(2): 316-344. doi:10.1177/1468796815616155.

Luthra, R., Platt, L., and Salamonska, J. (2016). Types of migration: The motivations, composition, and early integration patterns of 'new migrants' in Europe. International Migration Review. doi:10.1111/imre.12293.

Lynn, P., Gabler, S., Häder, S., and Laaksonen, S. (2007). Methods for achieving equivalence of samples in cross-national surveys. Journal of Official Statistics 23(1): 107-124.

Magnani, R., Sabin, K., Saidel, T., and Heckathorn, D. (2005). Review of sampling hard-to-reach and hidden populations for HIV surveillance. AIDS 19(2): S67S72. doi:10.1097/01.aids.0000172879.20628.e1.

McFall, S., Nandi, A., and Platt, L. (2017). Understanding Society user guide to ethnicity and immigration research. Colchester: ISER, University of Essex.

Nazroo, J., Berthoud, R., Erens, B., Karlsen, S., and Purdon, S. (2005). A longitudinal study of ethnic minorities: Focus and design (Report to the Economic and Social Research Council).

Platt, L., Luthra, R., and Frere-Smith, T. (2015). Adapting chain referral methods to sample new migrants: Possibilities and limitations. Demographic Research 33(24): 665-700. doi:10.4054/DemRes.2015.33.24. 
Portes, A., Fernandez-Kelly, P., and Haller, W. (2005). Segmented assimilation on the ground: The new second generation in early adulthood. Ethnic and Racial Studies 28(6): 1000-1040. doi:10.1080/01419870500224117.

Schmeets, H. (2015). Surveying immigrants in the Netherlands. (Working paper for expert workshop on immigrant surveys, Cologne, July 4-6, 2015).

Singer, E. (2002). The use of incentives to reduce nonresponse in household surveys. In: Groves, R.M., Dillman, D.A., Eltinge, J., and Little, R.J.A. (eds.). Survey nonresponse. New York: Wiley: 163-178.

Smith, P. (1997). Appendix: Survey methods. In: Modood, T., Berthoud, R., Lakey, J., Nazroo, J., Smith, P., Virdee, S., and Beishon, S. (eds.). Ethnic minorities in Britain: Diversity and disadvantage. London: Policy Studies Institute: 360-364.

Smith, P., Cleary, A., Jones, M., Johnston, S., Bremner, P., Brown, J., and Wiggins, R. (2011). A feasibility study for a survey of migrants. Sydney: University of Technology, Home Office (Report 2011-01). http://hdl.handle.net/10453/32013.

Sudman, S. and Kalton, G. (1986). New developments in the sampling of special populations. American Review of Sociology 12: 401-429. doi:10.1146/annurev. so.12.080186.002153.

Thompson, S.K. (1990). Adaptive cluster sampling. Journal of the American Statistical Association 85(412): 1050-1059. doi:10.1080/01621459.1990.10474975.

Tyldum, G. and Johnston, L. (2014). Applying respondent driven sampling to migrant populations: Lessons from the field. London: Palgrave Pivot. doi:10.1057/9781 137363619. 


\section{Appendix 1: The screening questionnaire}

Every household in the screening sample is first asked Q1.

Q1. Is there anyone living at this address who was born outside the United Kingdom, including children?

- Yes

- $\quad$ No

If the answer to Q1 is "yes," the household is screened in to the study; if the answer is "no" or the person is unsure, they are asked another question, Q2.

Q2. Does anyone living at this address come from any of the following ethnic groups, or have parents or grandparents from any of these groups, including children?

- None of these

- Indian

- Mixed Indian (parents or grandparents from Indian ethnic group and parents or grandparents from a non-Indian group)

- Pakistani

- Bangladeshi

- Sri Lankan

- Caribbean/West Indian

- Mixed Caribbean/West Indian (parents or grandparents from Caribbean/West Indian ethnic group and parents or grandparents from a non-Caribbean/West Indian ethnic group)

- North African

- Black African

- African Asian

- Chinese

- Far Eastern (includes Filipino, Thai, Malaysian, Japanese, Vietnamese, Singaporean, Indonesian, Korean, Burmese)

- Turkish

- Middle Eastern/Iranian (includes Israeli, Palestinian, Lebanese, Syrian, Jordanian, Yemeni, Saudi, Iraqi, Afghani, other Gulf states)

If the answer to Q2 is "yes," the household is screened in to the study. 
Lynn et al:: Design and implementation of a high-quality probability sample of immigrants

\section{Appendix 2: Questionnaire modules in IEMB}

\begin{tabular}{|c|c|c|}
\hline Module number & Module description & Who gets asked the questions \\
\hline 1 & $\mathrm{HH}$ grid & All \\
\hline 2 & $\mathrm{HH}$ questionnaire & All \\
\hline 3 & Individual intro & All \\
\hline 4 & Demographics & All \\
\hline 5 & Initial conditions & All \\
\hline 6 & Educational aspirations & Full-time student \\
\hline 7 & Family background & All \\
\hline 8 & Ethnicity and national identity & All \\
\hline 9 & Childhood language & All \\
\hline 10 & Language & All \\
\hline 11 & Language at home & All \\
\hline 12 & Religion & All \\
\hline 13 & Migration history & All \\
\hline 14 & Disability & All \\
\hline 15 & Health conditions & All \\
\hline 16 & Partnership history & All \\
\hline 17 & Fertility history & All \\
\hline 18 & Own first job & All \\
\hline 19 & Current employment & All \\
\hline 20 & Employees & Employees \\
\hline 21 & Self-employment & Self-employed \\
\hline 236 & Nonemployment & Unemployed \\
\hline 24 & Second jobs & All \\
\hline 25 & Childcare & Responsible for a child \\
\hline 28 & Benefits & All \\
\hline 29 & Household finances & All \\
\hline 31 & Casistart & All \\
\hline 32 & SF12 & Has agreed to self-completion \\
\hline 33 & $\mathrm{GHQ}$ & Has agreed to self-completion \\
\hline 35 & Living apart together (LAT) & $\begin{array}{l}\text { Has agreed to self-completion and } \\
\text { does not live with a spouse or partner }\end{array}$ \\
\hline 36 & Casiend & All \\
\hline 37 & Contact details & All \\
\hline 38 & Stable contact & All \\
\hline 39 & Interviewer observations & For interviewer to complete about the interview \\
\hline 40 & Proxy & Proxy interviews only \\
\hline
\end{tabular}


Table A-1: Sex and age composition within target ethnic and immigrant groups (weighted UKHLS-IEMS estimates)

\begin{tabular}{|c|c|c|c|c|c|c|c|c|}
\hline & \multicolumn{2}{|c|}{$\%$ Men (16+) } & \multicolumn{2}{|c|}{ Age $0-15, \%$} & \multicolumn{2}{|c|}{ Age $16-64, \%$} & \multicolumn{2}{|c|}{ Age $64+, \%$} \\
\hline & $\begin{array}{l}2011 \\
\text { Census }\end{array}$ & $\begin{array}{l}\text { UKHLS- } \\
\text { IEMS }\end{array}$ & $\begin{array}{l}2011 \\
\text { Census }\end{array}$ & $\begin{array}{l}\text { UKHLS- } \\
\text { IEMS }\end{array}$ & $\begin{array}{l}2011 \\
\text { Census }\end{array}$ & $\begin{array}{l}\text { UKHLS- } \\
\text { IEMS }\end{array}$ & $\begin{array}{l}2011 \\
\text { Census }\end{array}$ & $\begin{array}{l}\text { UKHLS- } \\
\text { IEMS }\end{array}$ \\
\hline Indian & 51 & 50 & 19 & 31 & 69 & 60 & 12 & 10 \\
\hline Pakistani & 51 & 49 & 33 & 47 & 61 & 49 & 6 & 4 \\
\hline Bangladeshi & 52 & 51 & 35 & 37 & 60 & 59 & 5 & 5 \\
\hline Black African & 48 & 47 & 30 & 40 & 66 & 57 & 4 & 4 \\
\hline Black Caribbean & 47 & 44 & 17 & 30 & 66 & 57 & 17 & 13 \\
\hline Immigrants $^{1}$ & 48 & 46 & 8 & 7 & 76 & 76 & 16 & 17 \\
\hline
\end{tabular}

Note: ${ }^{1}$ IEMB only as country of birth information was not collected about children in the other samples.

Table A-2: Ethnic group by highest qualifications (16+-year-olds), weighted estimates, includes proxy respondents

\begin{tabular}{lll}
\hline & Degree or higher $^{1}$ & \\
\hline Indian & 2011 Census, England and Wales (\%) & UKHLS-IEMS (\%) \\
Pakistani & 42 & 48 \\
Bangladeshi & 25 & 29 \\
Black African & 20 & 25 \\
Black Caribbean & 40 & 35 \\
Immigrants & 26 & 22 \\
\hline
\end{tabular}

Note: ${ }^{1}$ This corresponds to 'level 4 or higher' in the census tables and 'degree' in the UKHLS data.

Table A-3: Ethnic group by economic activity (16+-year-olds), weighted estimates

\begin{tabular}{|c|c|c|c|c|c|c|c|c|c|c|c|c|}
\hline & \multicolumn{2}{|c|}{ Employed (\%) } & \multicolumn{2}{|c|}{ Unemployed (\%) } & \multicolumn{2}{|c|}{ Retired (\%) } & \multicolumn{2}{|c|}{ Family (\%) } & \multicolumn{2}{|c|}{ Students (\%) } & \multicolumn{2}{|c|}{ Other (\%) } \\
\hline & $\begin{array}{l}2011 \\
\text { Census }\end{array}$ & $\begin{array}{l}\text { UKHLS- } \\
\text { IEMS }\end{array}$ & $\begin{array}{l}2011 \\
\text { Census }\end{array}$ & $\begin{array}{l}\text { UKHLS- } \\
\text { IEMS }\end{array}$ & $\begin{array}{l}2011 \\
\text { Census }\end{array}$ & $\begin{array}{l}\text { UKHLS- } \\
\text { IEMS }\end{array}$ & $\begin{array}{l}2011 \\
\text { Census }\end{array}$ & $\begin{array}{l}\text { UKHLS- } \\
\text { IEMS }\end{array}$ & $\begin{array}{l}2011 \\
\text { Census }\end{array}$ & $\begin{array}{l}\text { UKHLS- } \\
\text { IEMS }\end{array}$ & $\begin{array}{l}2011 \\
\text { Census }\end{array}$ & $\begin{array}{l}\text { UKHLS- } \\
\text { IEMS }\end{array}$ \\
\hline Indian & 64 & 66 & 6 & 6 & 10 & 11 & 5 & 8 & 8 & 8 & 7 & 1 \\
\hline Pakistani & 47 & 45 & 8 & 10 & 6 & 6 & 15 & 21 & 11 & 14 & 13 & 4 \\
\hline Bangladeshi & 46 & 49 & 10 & 10 & 6 & 4 & 16 & 19 & 11 & 12 & 11 & 6 \\
\hline Black African & 57 & 57 & 13 & 9 & 3 & 4 & 5 & 7 & 5 & 19 & 17 & 4 \\
\hline $\begin{array}{l}\text { Black } \\
\text { Caribbean }\end{array}$ & 57 & 60 & 10 & 10 & 16 & 14 & 3 & 3 & 3 & 8 & 11 & 5 \\
\hline $\begin{array}{l}\text { Born outside } \\
\text { United } \\
\text { Kingdom }\end{array}$ & 60 & 60 & 6 & 6 & 13 & 14 & 7 & 9 & 8 & 9 & 6 & 2 \\
\hline
\end{tabular}


Lynn et al:: Design and implementation of a high-quality probability sample of immigrants 